\title{
ALL THAT GLITTERS
}

Time is not kind to aesthetics. It strips ancient statuary of its pigments and makes the colours fade or darken, it rusts lustrous steel and draws a murky patina over silver and bronze. Capricious creatures that we are, we have come to develop a taste for this ageing of material surfaces. But early metallurgists might well be dismayed to see what has become of the shining objects they crafted. They might have been heartened, though, to know that their successors - today's scientists - are trying to reconstruct the original appearance of these materials.

Bronze, the alloy of copper and tin, is particularly compromised, generally becoming a dull brown over the ages. But it's widely acknowledged that the golden tint this alloy can display when freshly cast was one of the key attractions it held for ancient craftsmen. Indeed, the colour of bronze might have counted as much in its favour as its relative hardness for making weapons, armour and tools. As the pioneer of archaeometallurgy Cyril Stanley Smith noted ${ }^{1}$, the "desire to beautify the utilitarian has always stretched the ingenuity of the mechanics".

It has been argued ${ }^{2}$, for example, that a demand for bronze compositions resembling gold stimulated the transmission of metallurgical knowledge through the Balkan region in the fifth millennium $\mathrm{BC}$, where some of the earliest known bronze artefacts are found. And high-tin bronzes used in China for making mirrors don't have very good mechanical properties, but their lovely golden sheen was probably the reason they have the composition they do.

Bronzes with a very low tin content are close to the colour of copper, but with about 5 weight $\%$ of tin the alloys become pinkish. Add more tin and the hue turns yellowish, until finally compositions with more than about a quarter of tin by weight are silvercoloured. Ancient metallurgists also knew that they could modify the colour, and other properties, by adding small amounts of other elements, particularly arsenic. In fact, some of the very early bronzes are mixtures of just copper and arsenic, but the earliest of all, the fifth-millennium-BC Balkan bronzes, are alloys of copper and tin.

To try to understand how important the aesthetics of colour were in guiding the metallurgists of those ancient cultures, Radivojević et al. have now constructed a 'colour diagram' of the $\mathrm{Cu}-\mathrm{As}-\mathrm{Sn}$ ternary system $^{3}$. This is harder than it sounds, because there is no single way of characterizing colour for a reflective metallic material; among other things, the visual appearance is sensitive to surface texture too. The researchers made 64 different binary and ternary alloys and classified their colour both by photography and by spectrophotometric measurements of the reflected light.

The other complication is the use of arsenic. Radivojević, based at the University of Cambridge, collaborated with a team at the University of Belgrade not so much because of the geographical coincidence with the sources of early Balkan bronze artefacts but because the Serbian lab is one of the few in

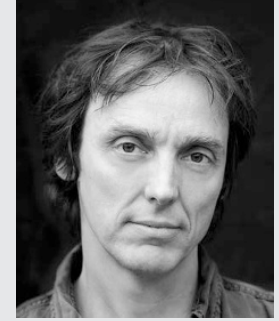

PHILIP BALL

Europe licensed to conduct such experiments with this highly toxic element. One shudders to think of the conditions in which the ancient metallurgists worked; it's safe to assume this was not a profession conducive to longevity.

The colours corresponding to the composition of some of the earliest Balkan tin bronzes indicate that those objects would have had a hue more like gold than copper, supporting the earlier contention of Radivojević et al. that aesthetics dictated their creation and demand ${ }^{2}$.

One might hope eventually to work out such things as colour from bandstructure calculations, where the arsenic is purely virtual and hazard-free. But it's far from clear whether $a b$ initio methods yet have the accuracy and sophistication for revealing such fine distinctions reliably, and so right now the answer must be sought in much the same way as craftsmen did nearly seven thousand years ago: by making.

\section{References}

1. Smith, C. S. A Search for Structure 325-331 (MIT Press, 1981)

2. Radivojević, M., Rehren, T., Kuzmanović-Cvetković, J., Jovanović, M. \& Northover, J. P. Antiquity 87, 1030-1045 (2013).

3. Radivojević, M. et al. J. Archaeol. Sci. https://doi. org/10.1016/j.jas.2017.12.001 (2017) 